\title{
Complexity and the Culture of Curriculum
}

\author{
WILLIAM E. DOLL, JR. \\ Louisiana State University (U.S.A.)
}

\begin{abstract}
This paper has two main foci: (1) the history of curriculum design, and (2) implications from the new sciences of chaos and complexity for the development of new forms of curriculum design and teaching implementation. Regarding the first focus, the paper posits that there exist-to use Wittgenstein's phrase - 'family resemblances' between Peter Ramus' 16th century curriculum design and that of Ralph Tyler in the 20th century. While this 400-year linkage is by no means linear, there are overlapping strands from Ramus to Comenius to the Puritans to colonial New England to Horace Mann to Ralph Tyler. What unites these strands, all belonging to the Protestant Methodization movement that swept across northern Europe into colonial America and the USA, is the concept of Method. Taylor's 'time and motion' studies set the stage for Tyler's Basic Principles of curriculum design - those starting with set goals and concluding with measured assessment. The second focus draws on the new sciences of chaos and complexity to develop a different sense of curriculum and instruction-open, dynamic, relational, creative, and systems oriented. The paper concludes with an integration of the rational/scientific with the aesthetic/spiritual into a view of education and curriculum informed by complexity.
\end{abstract}

Curriculum, as we know it, has always had a culture: Protestant. That is, since John Calvin in the mid-1500s appropriated the word, obviously Latin in origin, to mean a course, or path, of life (curriculum vitae), instead of a racetrack around which chariots sped (OED online, 2005), the word and concept of curriculum have been embedded in a Protestant, bourgeois, commercial/capitalist culture. ${ }^{1}$ The word curriculum, in our educational sense of 'a regular course of study or training, as at a school or university', leading to a degree or certification (OED online, 2005), was first used by a Peter Ramus (Petrus Ramus) — schoolmaster, headmaster, Regius Professor of Logic -in the late 16th century. ${ }^{2}$ Ramus' ordering of courses, indeed, all knowledge, is shown in the following Ramist map (or chart).

\footnotetext{
${ }^{1}$ While the connection between Protestantism and capitalism has been explored well by Max Weber in his magnificent text, Capitalism and the Spirit of Protestantism (1930/1996), only recently has the connection between education and Protestantism been explored. David Hamilton $(1989,1990,1992,2003)$ has taken the lead in this research, which is now being carried on, most ably, by Stephen Triche and Douglas McKnight (2004).

${ }^{2}$ I am indebted to Sean Buckreis for pointing out to me that C. Stephen Jaeger in his book, The Envy of Angels, dealing essentially with Cathedral schools in the 10th through 13th centuries, uses the word curriculum frequently (although there is no index reference of the word). Jaeger even gives a Latin phrase using the word curriculum: Quod unicum curriculum plerague veter
} 
WILLIAM E. DOLL, JR.

\section{A Ramist Map? \\ TA B VLA ARTIVM, QVAS IN \\ hoc Volumine coniunximus.}

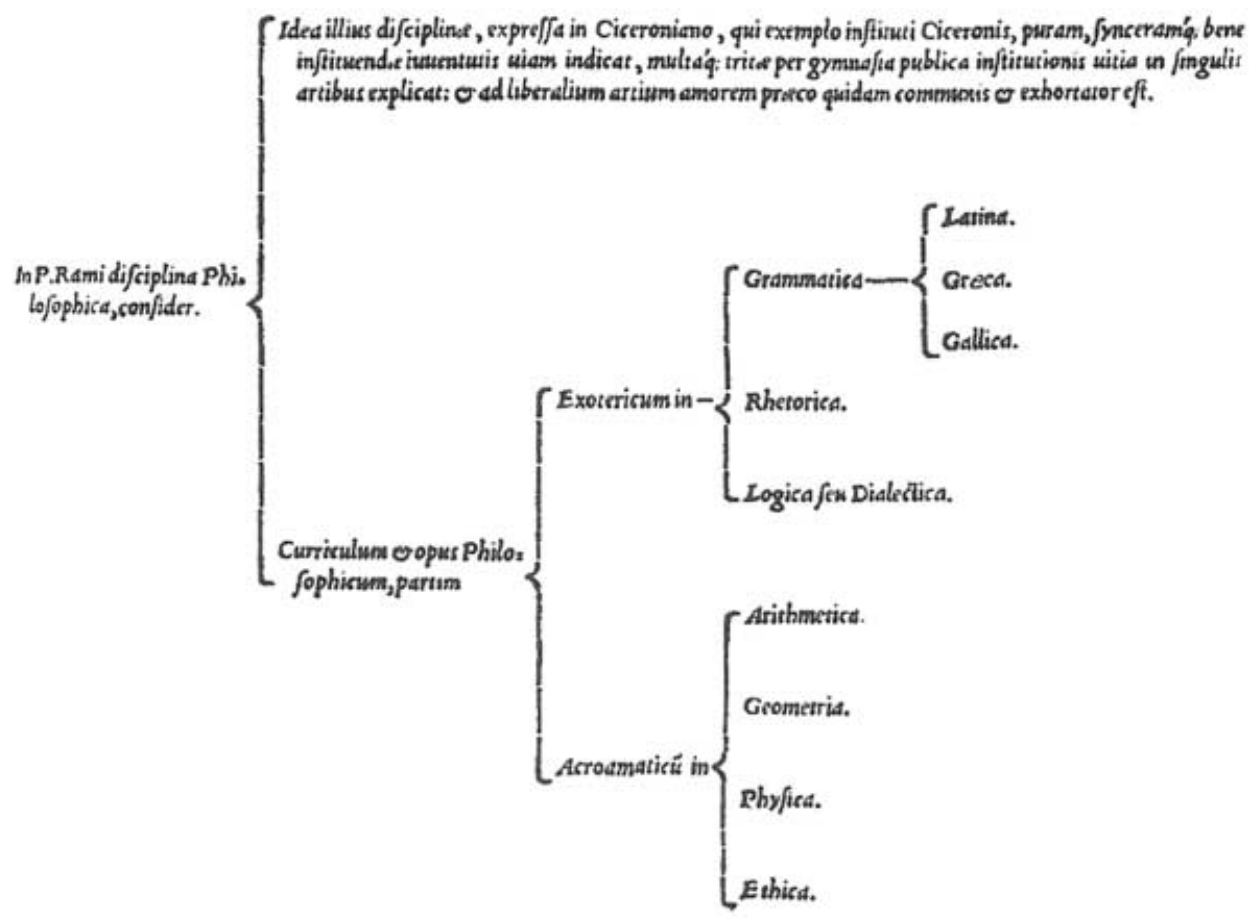

Source: P. Ramus, Professio regia, Basle, 1576.

Figure 1: A Ramist map

The word curriculum appears in the center left, classifying and organizing the Seven Liberal Arts as part of the work of philosophy. ${ }^{3}$ Prior to such a graphic

um studia sibi vindicar unt. Translating this phrase as 'Because most studies of the ancients claim for themselves a unique curriculum', it is possible, I believe (following Hamilton, as Triche \& McKnight do), to see this use of curriculum as a collection of texts (usually influenced by Cicero), with each school and/or school master having his own unique approach. The notion of curriculum as a uniform and predetermined set of courses all students in the university would follow (for the purpose of acquiring basic mastery in a subject or field) did not come until the early 17th century when Leiden and Glasgow adopted Ramus' uniform method. (See Triche \& McKnight, 2004.)

${ }^{3}$ The Latin writings say:

TABLE OF THE ARTS WHICH WE HAVE LISTED IN THIS VOLUME

In the Philosophic Discipline of P. Ramus, Consider:

(1) The idea of this discipline expressed in the Ciceronian corpus which by the example put into place by Cicero shows the pure way of well instituted learning and explores the many well-trodden faults of learning through public gymnasia and is a certain herald and extortion for the love of the liberal arts.

(2) Curriculum and Philosophic work separated into:

- Exoteric (suitable for the general public). 
representation, studies of the trivium (grammar, dialectic, rhetoric) and quadrivium (arithmetic, geometry, physics and ethics or music) were more loosely organized and there were considerable variations amongst schoolmasters. Utilizing the printing press, Ramus was able to provide-for wide distribution-an organizational chart of his approach to the organization of curriculum, thus 'methodizing' (and indeed universalizing) that which had previously been quite personal. Following in his footsteps, in the early 17th century, the universities of Glasgow (Scotland) and Leiden (the Netherlands) - both strongly Protestant--adopted the concept of curriculum, as a series of disciplinarily oriented courses leading to a degree, here a Bachelor's degree. ${ }^{4}$

Ramus' work in curriculum reform was most controversial: revered by the Protestants, especially the Puritans in England and America for its 'simple order' or 'plain style' (Doll et al., 2005, pp. 26-27; Triche \& McKnight, 2004, passim), it was dismissed as 'juvenile' and 'textbookish', fit only for 'youngsters in their early teens' - by many university scholars (Ong, 1958/1983, pp. 299-303). The notion of 'textbookizing' knowledge was a major part of Ramus' educational reform effort and part of the legacy he and his followers (of which there were thousands in the late 16th and early 17th centuries) have left us. ${ }^{5}$ David Hamilton (2003) makes this point quite explicitly when he states that Ramus' instructional methods have 'served as paradigms in the subsequent history of modern schooling' (2003, Abstract). While Ramus was not the first to bring a schooling concept to education, he was among the first in this movement and was undoubtedly the most influential. ${ }^{6}$

Ramus' methods (in both curriculum design and instructional delivery) have a lineage. I and others have argued elsewhere (Doll et al., 2005, Ch. 2; Triche \& McKnight, 2004, pp. 53-54) that this lineage runs from himself, through Johann Comenius and René Descartes, into Puritan thought on both sides of the Atlantic, then into New England schooling, to American 19th century schoolbooks and that century's efficiency movement (epitomized by Frederick Taylor), and comes to culmination in what today is

- Esoteric (suitable only to an enlightened inner circle).

${ }^{4}$ At this time, the candidate for the BA, always a male, one with a religious orientation, had to commence teaching before being fully accepted into the community of scholars. Hence our present term, commencement-or beginning of a teaching career. Those with a BA or MA or PhD were all expected to be teachers. Practitioners in the fields of law, medicine, even theology (or religious work) were not university trained.

${ }^{5}$ One of Ramus' major contributions to pedagogy, or the study of teaching, was to place the knowledge to be taught into textbook form. Such methodizing is with us today. Virtually a century ago, the philosopher, mathematician, logician, educator, A. N. Whitehead, said of teaching and textbooks:

In the schools of antiquity philosophers aspired to impart wisdom, in modern colleges our humbler aim is to teach subjects. The drop from divine wisdom ... to text-book knowledge of subjects ... marks an educational failure. (1929/1967, p. 29)

David Hamilton (2003), commenting on textbooks, says, 'Textbooks contain a deep contradiction: They are today's mediation of yesterday's knowledge', all in the light of predicting tomorrow's future (p. 8). Triche and McKnight (2004) say, '[textbooks] privilege organization, memory and mimicry' (p. 48).

${ }^{6}$ The best article I know on describing the relationship between schooling and Ramist methods is that by Stephen Triche and Douglas McKnight (2004). One of their arguments--that Ramus refined (and simplified for practical use), scholastic methods-takes an ironic twist in Kevin Gary's (2006) article. There, Gary points out that 'scholastics favored impersonal and systematic methods' (p. 127). Ramus did not alter this impersonalness; he just simplified the convolutions the scholastics used. Method with its sense of impersonal objectivity as opposed to Spirit with its sense of personal Being is a dichotomy that goes back not only to Ramus but also to the scholastics who drew heavily on their (Ciceronian) interpretation of Aristotle 
known as the Tyler Rationale. ${ }^{7}$ This long string of overlapping strands is the background against which we need to place the culture of complexity-a culture which embraces the complex and eschews the 'simplistic [and pietistic] view' of life held by the early founders of America's educational systems.

A reexamination of the Ramus map will show a version of the current corporate line-and-flow chart. Turn the map $90^{\circ}$ with the 'philosophy of Peter Ramus' at the north or top, and a corporate chart of organizational responsibilities flows. Power or control flows from the top (the most general) down to the bottom (the particular). This frame also occurs, although not in chart form, in the Tyler Rationale where broad, general goals permeate all. ${ }^{8}$ These goals and their language flow through the whole design. It is this design that dominates most lesson plans teachers are encouraged (often mandated) to develop and use. Virtually all 'methods' courses use this design. ${ }^{9}$

It is interesting to note that in this design the flow is top-down (deductive logic). It could also be bottom-up (inductive logic) but would still need to follow the linear hierarchy set up. Moving abductively, as both Charles Peirce and Gregory Bateson ${ }^{10}$ assert human thinking does-across, sideways, diagonally, or skipping over from node to node or idea to idea-is not possible in this frame. In short, Ramus' chart constricts human thinking-certainly it constricts creative thinking - and is an ironic twist on Protestantism's individual interpretation of the Christian Bible. As Andrew Grafton and Lisa Jardine (1986) point out though:

The individualism verging on hero-worship [of the great teachers] of early humanism gave way in the early seventeenth century to an ideology of routine, order, and above all, 'method'. (p. 123)

This sense of method being an ideology has been explored by myself and colleagues elsewhere (Doll \& Gough, 2002; Doll et al., 2005; Triche \& McKnight, 2004). There is no better word I know than ideology to explain the fascination, captivation even, Protestant thought had with an ordered and routine 'method'. Peter Dear (1995), in an insightful observation on Protestant method as contrasted with Catholic spirit, says:

Protestants would not accept the authority of Catholic tradition. Catholics held their tradition to be justified by the continual, behind-the-scenes guidance of the Holy Spirit.

\footnotetext{
${ }^{7}$ Herbert Kliebard (1995) has done exemplary work in analyzing the Tyler rationale and its foundational assumptions. While he does not connect this rationale to either Ramus or Descartes, as I do, his comments about the personal and arbitrary nature of Tyler's goals fits in nicely with Ramus' notion of 'placing first that which is first'; and his comments about the linear ordering (and reductionism) of the rationale's sequence fit nicely with Descartes' 'long chains of reasoning'. For my own comments on the Tyler Rationale, see my essay in Doll \& Gough, Curriculum Visions (2002).

${ }^{8}$ It is interesting to note that in the Rationale--(1) goals chosen, (2) experiences expressing the goals, (3) organization of the experiences, (4) assessment--the assessment is of how well the experiences and their organization are ordered to fit the goals. The goals themselves are not questioned, in either Tyler's or Ramus' frame.

${ }^{9}$ For a most interesting study about 'methods' and the nature of 'methods courses' in teachertraining, see Sarah Smitherman, 'Reflections on Teaching a Mathematics Education Course' (2006).

10 American pragmatist, Charles Sanders Peirce (1931), and later British / American anthropologist Gregory Bateson (1979), emphasize the importance of abduction in reasoned thought and in learning. Abduction, as an initial and playful phase of thought, arises from surprise or doubt, which itself arises from 'precepts'-pre-conscious senses of experience. Abduction, as it develops, leads to hypothesis formation and the pragmatic/ scientific method. In itself, abduction is the imaginative, creative play of thought necessary for more formal methods of thought to develop (Peirce, 1931, VI, pp. 452-91; Bateson, 1979, pp. 140-55). For both Peirce and Bateson, abductive play is necessary for creativity, for learning-especially learning which has a sense of self in it.
} 
Just so, humanisticly informed philosophers had their own functional equivalent of the Holy Spirit. It was something of a consuming interest by the end of the sixteenth century: Method. (p. 121) $)^{11}$

I believe the strength of this 'consuming interest', combined with the love of Ramus--he whom Increase Mather called 'that Great Scholar and Blessed Martyr' ${ }^{12}$ - which permeated the early American educational scene, helps explain why Frederick Taylor, two centuries later, with his time and motion studies considered it a 'moral duty' to have Schmidt load pig-iron at a rate of 48 tons per day, not at the usual $121 / 2$ tons he had previously done. ${ }^{13}$

This Ramist/ Protestant sense of method-separating knowledge from oral conversation, and bifurcating such knowledge into a hierarchal sequence of linear steps--has dominated scientific and intellectual thought from the 17th through 20th centuries, and remains a foundation for mainstream pedagogy today. ${ }^{14}$

\section{Chaotic Order}

The law of chaos is the law of ideas, of improvisations and seasons of belief. (Wallace Stevens, 'Extracts')

N. Katherine Hayles in her book on Chaos and Order (1991) remarks that in the latter decades of the 20th century an increasing interest in the relations between order and disorder (p. 1) developed in both the sciences and the humanities, particularly since the advent of the 'new sciences' (Gleick, 1987; Doll et al., 2005). Traditionally, in a modernist frame, this order/disorder relation has been seen as one of opposites; hence from this view, chaos having 'laws' is oxymoronic. By definition chaos is lawless. With the advent of the new sciences of chaos and complexity, though, scholars are realizing that both of these sciences are dealing with a complex sense of order, where order and disorder are structurally intertwined. Hayles says that each of these systems (chaos and complexity) deals with 'orderly disorder' (1991, p. 1). Such a phrase is no longer oxymoronic but is, rather, descriptive: descriptive of nature and its 'laws'. Hayles further comments, as do I (Doll, 1993), that the chaos/order dichotomous split is but another example of modernism's tendency to categorize. I trace this tendency to Ramus' charting and Aristotle's categorization. Hayles talks only of Aristotle's either/or (excluded middle) logic. Such logic with its sense of domination-right better than wrong-is being challenged today. The name of Michel Serres (1983; Serres \& Latour, 1995) comes to mind when one thinks of this challenge. Jayne Fleener's Curriculum Dynamics (2002) as

\footnotetext{
${ }^{11}$ The Puritan Protestants and the Wesleyan Methodists-rejecting the authority of King and Pope-were strong adherents to Method as 'the Way' - the one and only way.

${ }^{12}$ The hero worship of the Colonial Puritans (again see Triche \& McKnight, 2004) is really quite amazing. Not only were most theses done at Harvard College in the 1600s and 1700s filled with Ramus influences and citations, but at Perry Miller (1953) points out, it was Ramus to whom 'the Congregational theorist resorted', for every vexing question (Miller in Doll et al., 2005, p. 27).

${ }^{13}$ The story of Schmidt, a man 'strong as and dumb as an ox', and his exploitation by Taylor, as well as Taylor's rise and fall as the 'father of American efficiency', and his obsession with the moral implications of such efficiency, is well told by Robert Kanigel in his The One Best Way: Frederick Winslow Taylor and the Enigma of Efficiency (1997).

${ }^{14}$ Again, I know of no better work than that of Triche and McKnight (2004) to help one understand the nature of Ramus' method and its connection to the 'textbookizing' of knowledge. For an understanding of conversation-its history, power, possibility, and subjugation to the written word-see Donna Trueit, 2005.

It is interesting to note that American pragmatism's 'scientific method', with its emphasis not only on an idea's practical results but also on the origins of an idea in an individual's day-to-day experience, including an accumulation of pre- and sub-conscious registers, sidesteps Ramus' knowledge/ person dichotomy. (See Trueit, in preparation, 'Beyond Simple Order'.)
} 
well as our Chaos, Complexity, Curriculum and Culture (2005) offer insights into both a new logic, one of emergence and its importance for pedagogy (Osberg, 2005).

Important as Isaac Newton's scientific writings have been in the shaping of western science, it is his metaphysical assumptions that have given modernism's cultural milieu its distinctive flavor (Burtt, 1932/1955). Four of these assumptions are (1) that 'Nature is pleased with simplicity'; (2) 'To the same natural effect we must ... assign the same cause'; (3) 'God in the Beginning formed Matter into solid, massy, hard, impenetrable particles'; and (4) that 'Nature is conformable to herself and simple' (cited in Doll, 1993, pp. 20, 33, 36 -37). The third listed assumption, that Nature is made of solid atoms, reigned in science from the early 1700 s to the early 1900 s, at which time quanta concepts produced for us a very different picture (mostly inner space) of the atom. The notion of 'facts' existing as atomistic hardnesses, not as relations (as both A. N. Whitehead and Gregory Bateson argue) remains with us still, and dominates our sense of educational 'basics'. ${ }^{15}$

The second assumption, that of cause/effect, shows how in one particular instance chaos theory operates from a different set of presuppositions than do traditional pedagogical theories. Jacob Bronowski points out that since the 18th century a one- toone relation of cause to effect-small cause, small effect; large cause, large effect-'has been elevated to the rank of the central concept of science', arising as 'its guiding principle ... hence becoming our natural way of looking at all problems' (1978, p. 398, emphasis added). Such a mechanistic view (machine metaphor) underlies Pierre Simon de Laplace's linear predictability (understand the initial factors completely and the future history of the cosmos is predictable) ${ }^{16}$ behavior- ism's deterministic stimulusresponse (same effect arises from and indicates same cause); and teachers' faith in direct instruction (limited at best) and its (mis)placed honoring of repetition. Chaos theory, with its emphasis on nonlinearity (most 2nd order and all higher order mathematical equations) helps us realize that 'small causes can lead [not just to small, but also] to large effects' (Hayles, 1991, p. 11). The metaphor here, not mechanistic but dynamic, ${ }^{17}$ is that

\footnotetext{
${ }^{15}$ David Jardine, Patricia Clifford, and Sharon Friesen (2003) have done a fine job in calling into question just what is basic to teaching a curricular discipline. They assert that what is basic to teaching and learning is not merely the clear presentation nor 'understanding' of a subject's 'facts' - its 'bits and pieces' - but is rather an attitude and an activity. The attitude is one of opening oneself, as teacher or learner, to experiencing the situation at hand; the activity is immersing oneself in the situation fully enough for experiencing to happen (Introduction and passim). In such a view of teaching-learning, the facts of a subject exist not in isolation, separate from one another, but acquire their validity through their contextual relationship with other facts, with the discipline in which they are embedded, and with their relation to those experiencing the facts. Such a hermeneutical view of teaching-learning, while not part of the new sciences of chaos and complexity, is allied with them in offering an alternative to the analytical-referential (Reiss, 1982) frame which has dominated our (educational) discourse since the advent of modernism.

${ }^{16}$ Pierre Simon (Marquis) de LaPlace's 1776 statement, as quoted in Mullin (1993, p. 97) is:

The present state of nature is evidently a consequence of what it was in the preceding moment, and if we conceive of an intelligence which at a given instant comprehends all of the relations of the entities of this universe, it could state the respected positions, motions, and general effects of all these entities at any time in the past or future.

${ }^{17}$ The mechanistic system of Newton and others, that which dominated the early phases of the scientific revolution and which has left its metaphysical imprint on western thought since his time is really a simple form of dynamism-a push/pull form. As I have said, this metaphysical legacy is well detailed by Edwin Burtt (1932/1955). That which is commonly called dynamic today is really a complex dynamism, one coming from thermodynamics-dynamics built around heat and its transformative powers rather than a push / pull, reversible mechanism. It is an interesting aside that the potential (and transformative) power of fire/heat, when first developed by James Watt in the late 18th century, was quite an anomaly. The realization of its potential was slow in coming (Doll, 1993, p. 85, fn. 5) and it is only with Prigogine and his colleagues that a new
} 
of 'a butterfly flapping its wings in Brazil causing a typhoon in Tokyo'. Such a comment, dealing with the deterministic but unpredictable, is attributed to Edward Lorenz, whose seminal paper--'Deterministic Nonperiodic Flow' (1963)_brought forth the birth of a new science (Gleick, 1987; Bak, 1996; Capra, 1996; Lorenz, 1995) and thereby 'marked a perceptual change which was to alter the face of dynamical systems' (Holton \& May, 1993, pp. 98-99). ${ }^{18}$ It is this notion of a 'perceptual change'-particularly that dynamically structured--which both Katherine Hayles (1991) and Lee Smolin (2001) emphasize as being so important in seeing the possibilities inherent in chaos and complexity theories.

The first and fourth assumptions, that 'Nature is pleased with simplicity', and that 'Nature is conformable to herself and simple', present not only the sharpest contrast with chaos and complexity theories but also the greatest opportunity for these two theories to develop their senses of being. The simplicity of which Newton speaks has strong Puritan overtones whose worship of 'simple piety' led them to pay great honor to Peter Ramus. In contrast, Prigogine \& Stengers (1984) point out that the 'night sky' of today does not show us the simple order of 'stars fixed in their firmament' but shows us rather 'strange objects: pulsars, galaxies exploding and being torn apart; stars that, we are told, collapse into "black holes" irreversibly devouring all they manage to ensnare' (p. 214). In short, the cosmos is turbulent and it is turbulence that so fascinated chemist Prigogine. He posits that turbulence, particularly thermodynamic turbulence, with its unstable dynamic and dissipative heat structures actually gives birth to new structures. In Donna Trueit's (2005) sense, the new emerges from (indeed needs) the imbalance of a dissipative structure. Rather than being conformable to itself in a simple sense, our universe is complexly conformable, continually recreating and transforming itself through the dynamic activity of dissipative structures. 'Orderly disorder' seems to be a fine phrase for this phenomenon, and imbalance the state in which this phenomenon occurs.

The phrase 'dissipative structure' is on first look an oxymoron, for with enough dissipation the structure becomes no longer-it wastes away. A heat engine, such as a locomotive, dissipates or wastes energy as it functions. Too much waste or dissipation (escaping of heat / energy) and the machine stops functioning. ${ }^{19}$ Lord Kelvin (William Thompson) applied this idea of dissipation to the universe in general, giving us the notion of the universe's 'heat death' - through dissipation of the sun's energy. The second law of thermodynamics states that this wasting away is universal, all objects in the universe tending toward maximum dissipation or entropy. Entropy was one of the big E's of the 19th century (Doll, 1993, ch. 4). But what about living organisms, indeed, living systems? The other big E of the 19th century was Evolution, the progressive

metaphysics, one built around thermodynamics and its 'dissipative structure' has begun to emerge. (See particularly Prigogine, 1997.)

${ }^{18}$ Ilya Prigogine (with his collaborative author, Isabelle Stengers) in his Postscript to Michel Serres' Hermes (1983) points out that the dynamics of classical systems such as that of Isaac Newton's atoms or Gottfried Wilhelm von Leibniz's monads is but one sort of dynamic system. As Prigogine says:

Dynamics has discovered today that as soon as the dynamic system to be described is no longer completely simple, the determinist description cannot be realized.... There are dynamic systems of different sorts (p. 150, emphasis added).

In this change, Prigogine and Serres realize that 'observation disappears in favor of relations'. This means that in 'Man's New Dialogue with Nature', to use the subtitle of Prigogine and Stengers' 1984 book, relations and their patterns replace observation and its data collection. This change, revolutionary in its import, educational thought has not yet assimilated.

${ }^{19}$ It is interesting to speculate to what degree the second law of thermodynamics is actually based on classical, push-pull dynamics and not on thermodynamics, which may well have transformative powers built into its very structure. 
development or 'spontaneous increase in organization in living organisms'. Contrasting these two phenomena, Katherine Hayles (1990) comments that Lord Kelvin 'agonized in print over whether living organisms were an exception' to the law of 'universal dissipation'. He finally concluded it was futile to worry about the matter ... [since] the real phenomena of life infinitely transcend human science' (p. 93).

Ilya Prigogine problematizes the issue of entropy (the dying of the universe) and negentropy (the universe's creative thrust) via his notion of structures far-fromequilibrium - structures which with their inherent unstable dynamics and turbulences (earthquakes, hurricanes, tornadoes, and tsunamis) are highly unbalanced, but still str uctured. Here Prigogine posits imbalance as a source of creativity. In a closed, mechanistic, equilibrium oriented system (as a heat engine) imbalance and disorder are to be avoided, lessened, negated. In an open, living, far-from-equilibrium system (life itself ), an orderly disorder is the very source of creativity. ${ }^{20}$

\section{Complexity's Features}

Obviously chaos and complexity are intertwined-both accept disorder as a natural part of order, both utilize nonlinear, recursive equations in the mathematical work they rely on, and both see Nature from a non-Newtonian perspective (complex not simple). There are, though, important differences. Chaos theory, often called deterministic chaos theory, uses nonlinear mathematics to study the turbulences of nature (those on the very edge of order/disorder) for the purpose of controlling (at least in the short term) those turbulences. While the determinism it espouses is an unpredictable determinism (due to the myriad of ever changing factors entering any situation or event), the goal is one of control and the methods (mathematical in nature) are quite rational. ${ }^{21}$

Chaos theory arose from the turn of the 20th century's three-body problem, one that emerged with the introduction of 'the third' into a dyadic relationship. ${ }^{22}$ This is a

\footnotetext{
${ }^{20}$ Michel Serres, in a most fascinating article $(1983$, ch. 7$)$, puts forth the proposition that the categorical distinction modernism makes between entropy/negentropy, order/ disorder, closed/open, chaos/structure, noise/information, global/local is really one of levels of perception. What one sees at one level - the chaotic noise in a classroom (say) - is seen as structured information at another level. This 'ambiguity function' occurs at the boundaries of any system and has its own 'laws'. To adopt one level only is to place oneself inside a box (or bottle) from which extradition is most difficult. What is needed is a multi- perspectival view, one that moves beyond an either/or dichotomy to accept a both/and frame. Brent Davis considers, in some depth, this issue in his paper in Educational Philosophy and Theory, Volume 40, Number 1 (2008).

${ }^{21}$ The history and nature of chaos is well described by Tom Mullin, 1993 and by Edward Lorenz, 1995.

${ }^{22}$ The difficulty Newton's equations of gravity have when a third body-say the moon-- is introduced into the dyadic, gravitational relationship of the sun and the earth (or when the sun is introduced into the dyadic, gravitational relationship of the moon and the earth) was well known in Newton's day, indeed by Newton himself. The assumption though was that Newton's calculus (linear in nature) could indeed solve the three-body problem with a few more facts and maybe some equational adjustments. This assumption reinforced the then prevalent belief that the universe was stable, uniform, and simply ordered.

In 1887 King Oscar II of Sweden asked if one could prove that indeed the universe was stable. Henri Poincaré worked on the problem and to his amazement found that not only could he not so prove, but also neither could anyone else with the mathematics of the day (linear). It would require non-linear mathematics to so prove, and then the proof would be that the universe was not 'simply' stable, but was stable only in a dynamic, non-predictable sense: Prediction devient impossible. There are too many works on the history of the 'three-body problem' for me to mention here. One I found most useful was Ian Stewart's Does God Play Dice? (1990). Here he not only talks of the 'three-body problem', but also of how, in working on it (early 20th century), Poincaré brought forth the 'whole towering edifice' of topology (p. 64 ff.).
} 
problem French mathematician Jules Henri Poincaré said was impossible to solve with the conceptual (linear) framework of mathematics of the time: prediction devient impossible. ${ }^{23}$ Complexity theory, allied with chaos theory through the utilization both make of nonlinear processes (especially iteration and fractal dimensions), came later in the century with the realization that nature itself is fractaled and self-organizing (Bak, 1996). It is these two concepts-fractalness and self-organization-that characterize the 'nature' of complexity.

\section{A Systems View}

I will focus here on self-organization and its relation to systems theory, since both chaos and complexity come under the large umbrella of complex adaptive systems (Stanley, 2005, in Doll et al., ch. 5). A modern systems approach is generally credited to Ludwig von Bertalanffy (1901-1972), who formalized his thoughts into a General System Theory first in articles in the 1940s and 1950s and later (in a book edition) in 1968. While a practicing biologist all his life-the inventor of the Bertalanffy Method of cellular screening for cancer as a determiner of the need for a biopsy- Bertalanffy was mostly drawn to theoretical biology, which he saw as the interface of biology with philosophy. As his wife, Maria, told him when, as a young student in Vienna, he was deciding what course his career should take: 'A biologist can use what he knows to be a philosopher, but it cannot work the other way around' (in Davidson, 1983, p. 53). ${ }^{24}$

As a theoretical biologist, Bertalanffy was drawn to the notion of organization, particularly developmental organization. Developmental organization, as in evolution, has a hierarchical frame to it. ${ }^{25}$ This is to say that the wholeness of the cell, made up of molecule parts, is itself part of a more comprehensive form of organization, the human body, which in turn is part of a social enclave, itself part of a biosphere, etc. Thus, the part-whole relationship is a nested one-each whole, as a collection of interacting elements or parts, being itself part of a more inclusive whole. What fascinated

${ }^{23}$ David Holton and (Lord) Robert May in their 1993 article point out that back in 1903

Henri Poincaré stated, 'It may happen that small differences in initial conditions produce very great ones in the final phenomena' (p. 97). The power and usefulness of this point, though, lay rather dormant for the next seventy-five years, until mathematical pioneers Tien-Yien Li and James Yorke, Robert May, and Edward Lorenz began (with the use of computers) to see the possibilities inherent in adopting a nonlinear viewpoint.

Expanding on the notion of the sensitivity of initial conditions, Poincaré in 1905 made a direct challenge to LaPlace's determinism:

Even if it were the case that the natural laws had no longer any secret for us we could still know the initial conditions only approximately ... (and since a) small error (in these conditions) will produce an enormous error (later on) prediction becomes impossiblePrediction devient impossible. (Poincaré in Doll et al., 2005, p. 137)

Mark Davidson's Uncommon Sense (1983), written with the aid of Maria Bertalanffy. In addition to Bertalanffy's own writings, I have drawn on Erwin Laszlo's The Systems View of the World (1972).

${ }^{24}$ This section on the life and thoughts of Ludwig von Bertalanffy is drawn mostly from Mark Davidson's Uncommon Sense (1983), written with the aid of Maria Bertalanffy. In addition to Bertalanffy's own writings, I have drawn on Erwin Laszlo's The Systems View of the World (1972).

${ }^{25}$ Davidson (1983) has a nice bon mot from Bertalanffy regarding evolution: 'From the standpoint of general biology, the fundamental issue of evolution is not the origin of the species. It is the origin of organization' (p. 91).

The concept of hierarchy, prominent in evolution as each specie's transformation brings along with it increased ability to interact with (and control) the environment in which we are all enmeshed, also has the unfortunate social connotation (social Darwinism) of one group-essentially white, European males-being 'better' than other groups. The social disasters this linear line of thinking has promulgated are too numerous to name. One chaos/complexity theorist to provide an alternative to this form of thinking is Michel Serres. 
Bertalanffy so much in this doubled relationship of wholes depending upon parts and parts depending upon wholes, is that of elements standing, not alone, but in interrelation. In Chapter 3 of his General System Theory (1968) he shows four dots unconnected:

and then connects the dots via a linear sequence,

and also as a square.
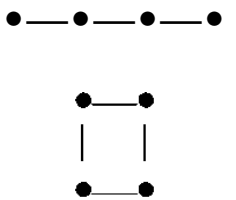

He comments that once we see the dots connected, then we know 'not only the elements but also the relations between them' (p. 54). He then goes on to define a system 'as a set of elements standing in inter relations' (p. 55, emphasis added). The systems encapsulating these interrelations need to be, for Bertalanffy, open systems. While in nature both open and closed systems have external relations, are 'fed' in one way or another by outside forces, closed systems function toward a pre- set goal, such as in the workings of a thermostat. Open systems, in differentiation, function to keep just the right amount of imbalance, so that the systems might maintain a creative dynamism. The human body, democratic social systems, and the cosmos itself are all illustrations of open systems. Whereas closed systems 'exchange energy but no matter', open systems 'exchange both energy and matter' (Prigogine, 1961, p. 3) and thus can transform matter into energy, as in an atomic explosion. ${ }^{26}$ In simple terms, ones important for education, closed systems transfer and transmit, open systems transform. Analogously, direct instruction, with its simplicity, would exemplify a closed system approach while interpretative inquiry, with its complexity, would exemplify an open systems approach.

Bertalanffy, with his biological background, definitely advocated the study, in many forms, of open systems. As Davidson (1983, p. 83) notes, Bertalanffy considered his emphasis on and development of open systems to be 'one of his most important accomplishments'. Its importance is certainly evident in Bertalanffy's General System Theory (1968) where chapter 6 is devoted to 'The Model of Open System'. In essays put forth under the title A Systems View of Man (1981), Bertalanffy makes many cogent remarks about open systems, and especially his belief about their inherent creative power.

Against this background it is quite amazing, but true, that as time went on in Bertalanffy's career he became associated, particularly after the Macy conferences of the post-WW II years, ${ }^{27}$ with a closed, mechanistic, engineering view of systems. This view he called 'the darker aspects of this (systems) development' (in Davidson, 1983, p. 208). It remained for Ilya Prigogine and his colleagues to bring forward the positive aspects of open systems, a concept Bertalanffy fathered. The educational implications of an open systems frame are just now beginning to emerge (see Davis \& Sumara, 2006; Doll, 1993; Doll \& Gough, 2002, with Doll et al., 2005; and Fleener, 2002), and allied with this approach is the work being done by David Jardine, Pat Clifford, and Sharon Friesen, 2003 \& 2006).

Quite akin to Jean Piaget's sense of 'equilibration' (a word Bertalanffy uses [1981, p. 36]), Bertalanffy talks of the living organism, the epitome of an open system, as one that "does more than maintain its equilibrium" '. 'As long as it lives, it [the open system]

\footnotetext{
${ }^{26}$ More on open and closed systems can be found in Doll (1993, Part II and passim). The nature of open (thermodynamic) systems underlies all the work Prigogine did in his lifetime, and for which he won the Nobel Prize in Chemistry in 1977.

${ }^{27}$ While there are many books on these conferences, held in New York City from 1943-1954, the one I find most informative is N. Katherine Hayles' How We Became Posthuman (1999).
} 
maintains a disequilibrium', a state Bertalanffy defines as 'steady'. Such steadiness though is not the steadiness of a closed, stable system; rather, the steadiness of an open system is a dynamic or unstable steadiness, one where through its own (inter)activity, the system maintains an 'imbalance', neither too great nor too small, but of just 'the right amount' (Doll, 1993, p. 176) for the system to be continually active. In this activity, developmental and progressive, the organism has the power and creative urge to move (transform itself) to 'higher forms of order and organization' (Bertalanffy, 1981, p. 36). In his analysis of this equilibration ('orderly disorder') process, Bertalanffy goes on to make some trenchant and most useful comments about the nature of open systems. An open system, existing in what C. H. Waddington (1957) would call a homeorhetic (as opposed to homeostatic) state, exhibits a dynamic, creative steadiness. This state possesses the power of transformation. Educationally this is not a state of teaching or learning where mimesis holds forth, but is one where play, poiesis, and possibility reign (Trueit, 2005, in preparation). Bertalanffy goes on to state that while the final conditions of a closed state are 'determined by the initial conditions' [the setting of a thermostat], the further (never final) conditions of transformation in an open system emerge from the long-term interactions within and by the system itself. ${ }^{28}$ Educationally such an interactive frame not only calls into question, but actually negates, such time honored practices as setting an I.Q. for each person, averaging grades, and dividing a school into various sequential units. None of these pays attention to transformative development over time. This latter point leads to Bertalanffy's final one regarding open systems-a point central to all of Ilya Prigogine's work. In open systems, especially in the living world, human and ecological, there can be found 'a transition [I'd say transformation] toward states of higher order', states which 'seemingly contradict... the second principle of thermodynamics' (1981, p. 113). 'Open systems [he goes on to say] may exhibit antientropic processes and develop toward states of higher order, differentiation, and organization'.

\section{Complex Organization}

Where monadic physics ends and trajectories become unstable, the world of the irreversible begins, the open world in which, through fluctuations and bifurcations, things are born, grown, and die. (Prigogine \& Stengers, 1983, 'Postface' in Michel Serres, Hermes)

The systems view is the emerging contemporary view of organized complexity, one step beyond the Newtonian view of organized simplicity, and two steps beyond the classical world views of divinely ordered or imaginatively envisaged complexity. (Laszlo, 1972, The Systems View of the World)

\footnotetext{
${ }^{28}$ For Prigogine the long-term interactions of the system inevitably lead-by the very nature of their being long-term (inter)actions-away from equilibrium with its universality, stability, even deadness, to states far-from-equilibrium where newness (birth) occurs, as time (with its arrow) takes on developmental and irreversible dimensions. Writing with Stengers (1983) and combining their voices with that of Michel Serres they state:

Nature does not code the universal...; there is no code at the equilibrium point. Everything that exists, all the individual bodies that come into being, coded circumstances, tablets with their own law, do so by distancing themselves from the law without a memory of the law of ... the stable and infinite ... , [the law of ] equilibrium, thus forgetting the specificity of initial states. (p. 155)

The new laws, those with a memory, arising from the process of equilibration or dissipation or imbalance--inherent in chaos and complexity theories-Prigogine brings forth in his final book, The End of Certainty: Time, Chaos, and the New Laws of Nature (1997). These new laws, dialogical and conversational, one's embracing ambiguity and uncertainty, have yet to be studied by educators. Chaos and complexity theories encourage such study.
} 
One of the most unusual, and most characteristic, features of complex organization is the ability of the complex to develop states of higher (that is more comprehensive) order, differentiation and organization; indeed to create newness from itself via its interactions. In Stuart Kauffman's phrase, the interaction of elements in this complex organization produces 'order for free'. Kauffman, a MacArthur Fellow at the Santa Fe Institute (for the study of complex systems), ${ }^{29}$ following in the foot- steps of both Ludwig von Bertalanffy and Ilya Prigogine (and certainly alongside those of A. N. Whitehead and Gregory Bateson), focuses on The Origins of Order (1993). In this book, the first of three, Kauffman speculates that life began not in Jacques Monod's elegant phrase, as 'chance caught on a wing' (p. xv), nor as the creationists believe as a direct gift from God. Between these two positions, which Kauffman sees as extremes, there lies space for selforganization, indeed self- creation, to arise from 'modestly complex' structures. As he says:

I want to suggest that we can think of the origin of life as an expected emergent collective property of a modestly complex mixture of catalytic polymers, such as proteins or catalytic RNA, which catalyze one another's formation. I believe that the origin of life was not an enormously improbable event, but law-like and governed by new principles of self- organization in complex webs of catalysts. (p. xvi, emphasis in original)

Using Kauffman's ideas as a generative framework (not as a model) for our own educational thoughts I believe it is possible for 'meaning' and 'understanding' —at a deeper, less superficial level than textbooks provide-to come forward in a 'modestly complex mixture', or webs of catalysts. That is, if we modify just a bit A. N. Whitehead's (1929/1967) dictum of 'throwing ideas into every combination conceivable' (p. 2) we might be able to design curricula or instructional strategies where ideas interacting with other ideas will catalyze themselves to develop (create) not only other ideas but ones more adaptable to the issues or problems at hand. As simple and practical (and indeed practiced) as this suggestion is, we have never developed a theory to underpin this suggestion and to carry it forward beyond the cliché of 'brainstorming'. In his next book, At Home in the Universe (1995), Kauffman brings forth suggestions around the idea of self-organization, which I believe do help us develop a practical pedagogy based on meaning and understanding arising spontaneously from modestly complex interactions.

The notion of 'modestly complex interactions' is an important one for Kauffmanfor while his interactions (computer simulated and biological) are complex, in a robust and rich way, they do arise from sets of simples, which, as simples, affect, guide, and ultimately provide a measure of constraint or control over the emergence of the complex interactions. ${ }^{30}$ Such modestly complex interactions are generative for those of us using complexity theory to develop educational frames. Before going into some detail regarding Kauffman's argument-that certain (robust) complex systems have a natural 'penchant for exhibiting convergent ... flow' (in Brockman, 1995, p. 337) ${ }^{31}-\mathrm{I}^{\prime} \mathrm{d}$ like to make a comment about the idea of the sacred, which appears in the opening chapters of his 1995 book and especially in his acknowledgement of the role Johnson played in

\footnotetext{
${ }^{29}$ A most interesting book describing this institute is George Johnson's Fire in the Mind (1996). Here the connection between the sacred and the complex begins to emerge.

${ }^{30}$ Stephen Gould in his critique sees Kauffman 'following in the structuralist tradition' and believes that his " order for free" is an outcome of sets of constraints'. Daniel Dennett in his critique worries that Kauffman comes close to seeing 'the divine hand of God in the workings of nature' (in Brockman, 1995, pp. 340-341).

${ }^{31}$ By 'convergent [not divergent] flow', Kauffman means that what we see (on the surface) as random may well (under certain circumstances) have a deeper hidden order. Finding these certain circumstances (located, Kauffman believes, in open, far-from-equilibrium systems) is one of his main tasks.
} 
helping Kauffman 'clarify and structure' his thoughts. As they hiked, together, the rugged landscape behind Santa Fe, chapter after chapter of Kauffman's book emerged. ${ }^{32}$ Kauffman even offered Johnson a co-authoring of the book. Johnson graciously declined, writing his own book (1996) on faith and science as Kauffman wrote his on selforganization and complexity. The two books are intertwined though-Johnson talks about Kauffman, while Kauffman echoes Johnson's theme of connecting the sacred with the scientific. To quote Kauffman at the beginning of his book:

Even though science has advanced over the decades and centuries, 'a spiritual hunger remains', a hunger that cannot be satisfied by science alone but yearns for us 'to find anew our place in the universe ... [a place where] we recover our sense of worth, of the sacred'. (1995, pp. $4-5)$

Not many, indeed none I know, have made a connection between the science of complexity and the sacredness of being, yet this is a persistent theme as Kauffman looks at our species and its place or home in the universe. This is a theme, I believe, worth exploring. It is a theme Kauffman returns to in the final paragraphs of his book.

As I have said, Kauffman's scientific and spiritual theme is that in 'living systems' there is an underlying 'deep theory of biological order' (p. 18). When the systems are complex-open and far-from-equilibrium-they may, indeed it is almost certain they will, creatively develop new systems. Order will now emerge 'for free'. Kauffman's theory is deep in two ways-one way is that it applies to multiple situations, those near equilibrium, far-from-equilibrium (which are near the edge of chaos), and even to those in the chaotic realm just on the edge of chaos. For most cellular life 'equilibrium corresponds to death' (p. 21); thus there is neither robustness nor richness to life in an equilibrium situation. I would say the same occurs in teaching where teaching is no more than telling - a situation A. N. Whitehead (1929/1967) calls 'dead', 'inert', 'useless', 'barren' and full of 'mental dryrot' (chs. 1, 2, 3, passim). Behavior in the chaotic realm (where the interactions are more than modestly complex) is overly sensitive to slight changes. Thus, 'any small change in a chaotic system can, and typically does have large and amplifying effects', making such a situation too fragile for any sort of sustained emergence to last (Kauffman, 1995, p. 19).$^{33}$ Rather, the robustness of life Kauffman sees outside his Santa Fe window - a 'bubbling activity', rich and generative, an 'ordered complexity'-comes, he believes, from intermediate situations, far-from-equilibrium where 'a kind of collective crystallization of spontaneous structure' emerges (pp. 18-19). This sort of imbalanced, dynamic situation, one of non-equilibrium (which Kauffman, like Prigogine, believes is the 'natural' one for the universe) is where life and creativity are prominent. This intermediate situation between order and chaos is where selforganization occurs. The other way in which Kauffman's theory of biological order is 'deep', is that opposed to reductionism and its insistence on the precision of details (a precision Whitehead called 'misplaced concreteness): 'the core phenomena of the deepest importance do not depend on all the details' $(1995$, p. 18). In the vernacular, focusing on such details leads one to 'miss the forest for the trees', a criticism which can

\footnotetext{
${ }^{32}$ I am suggesting here, really speculating, on the relation between these weekly hikes the two men took and the 'fitness landscapes', which play such an important role in Kauffman's notion of emergence in evolution, especially in co-evolution--'organisms adapt by genetic changes, [ever] seeking to improve their fitness'. But as we as organisms adapt, 'so do our competitors: [and] to remain fit, we must adapt to their adaptations. In coevolving systems, each partner clambers up its fitness landscape toward fitness peaks' (1995, p. 27). Those organisms/systems which seem most able to adapt and survive (reproduce and have influence) are the ones near (but not on) the 'edge of chaos'. Such far-from-equilibrium systems are the ones Prigogine also studied and called 'dissipative structures' (p. 53).

${ }^{33}$ Kauffman sees chaos and complexity as different, with 'chaos as a subset of complexity' (in Brockman, p. 334).
} 
certainly be leveled at the United States' 2000 educational movement of 'No Child Left Behind'.

Taking an approach of 'Unrepentant Holism' (p. 69), Kauffman sets out to explain 'an order whose origin and character ... (are) independent of the details' (p. 18): in other words, this order is ubiquitous throughout the universe, where 'development arises almost without regard to how networks of interacting genes [or elements] are strung together' (p. 18). In common parlance, there are many pathways to development, biological and intellectual; there is no 'one and only way'. Certainly, for an order which 'springs forth', which arises spontaneously from interactions, there is no pre-set way. Whatever 'method' our universe is using for its ordering, it must have flexibility. ${ }^{34}$ Kauffman's basic assumption-a metaphysical, sacred, ${ }^{35}$ and controversial one-is that inside the universe there is a deep, 'living' order (p. 304) - one of systems selforganizing themselves, via networks, inside these systems, catalyzing themselves (pp. 47-66).

Kauffman approaches his investigations (which, incidentally, is the title of his third book [2000]) of self-organizing systems by looking first at the systems structure of Boolean networks. He chooses a Boolean network for its 0 and 1 algebra, which corresponds nicely with switchings (on/off) in both a computer circuit and a genetic, neuronal one. He has spent over three decades playing with these structures. Kauffman and his associates apply this structure with its on / off workings first to a network of light bulbs, then speculatively to evolution, and finally, even more speculatively, to social systems. $^{36}$

As a theoretical biologist, Kauffman assumes that 'in a chemical soup', when the number of different kinds of molecules passes a certain threshold-an autocatalytic metabolism suddenly appears (p. 47). ${ }^{37}$ To test this hypothesis Kauffman and his colleagues built various circuit boards of connecting light bulbs. The bulbs were connected randomly, one to another: that is, bulb A was connected to bulb B and/or bulb C and / or bulb D, etc. The number of bulbs was labeled $\mathrm{N}$ and the connections of each bulb, anywhere from one to twenty, labeled K. Since the connections were random

${ }^{34}$ It is, of course, this concept of a method having flexibility that distinguishes Kauffman's method from the rigid one of Ramus and Tyler. Flexibility is also the ingredient that keeps Kauffman's method in the looser teleological realm. For more on this realm, see Doll, 1993, p. 82.

${ }^{35}$ Near the end of his (1995) book, Kauffman queries: 'Has not our Baconian tradition, which celebrates science as the power to predict and control, also brought us a secular loss of awe and respect?' He then goes on,

If science lost us our Western paradise, our place at the center of the world, children of God, with the sun cycling overhead and the birds of the air, beasts of the field, and fish of the waters placed there for our bounty, if we have been left adrift near the edge of just another humdrum galaxy, perhaps it is time to take heartened stock of our situation.

If the theories of emergence we have discussed here have merit, perhaps we are at home in the universe in ways we have not known.... I do not know if the stories of emergence we have discussed in this book will prove to be correct. But these stories are not evidently foolish. They are bits and pieces of a new arena of science, a science that will grow in the coming decades toward some new view of emergence and order in this far-from-equilibrium universe that is our home (pp. 302- 04).

${ }^{36}$ I shall not in this paper deal with Kauffman's speculations on the complexity of social systems other than to say that he believes democracy may be the best form of governmental organization possible, not for its perfections, but for its imperfections- ones which keep the system alive, dynamic, ever evolving.

${ }_{37}$ This paraphrased comment is much akin to those Prigogine and Stengers (1983) make in commenting on Serres' clinamen: 'When trajectories become unstable [as do all laminar flows beyond a certain threshold of velocity] the world of the irreversible begins, the open world in which, through fluctuations and bifurcations, things are born, grow, die'. Here are 'the selforganizing processes that make up nature' (pp. 152 and 154). 
many bulbs, when electrified, became schizophrenic, receiving an order to turn on from one connection and off from another. As electric current was fed into the circuit board, the light bulbs lit-sometimes this lighting produced a stable or 'frozen' state; sometimes the lighting went on and on and on blinking, blinking, blinking with no pattern emerging. To create what he wanted-order arising from random connections ('order for free') Kauffman found he needed a large circuit board with many bulbs (he finally settled on a board of 100,000 bulbs). The connections, though, needed to be sparse-only 1 or 2 connections per bulb. With a higher number of connections, order did not emerge. When many bulbs, though, were connected 'sparsely', the randomness of the blinking bulbs would eventually develop (cycle) into patterns of interesting and varied orders. Kauffman calls this 'order for free' (ch. 4). To quote Kauffman:

Sparsely connected networks exhibit internal order; densely connected ones veer into chaos; and networks with a single connection per element freeze into mindlessly dull behavior. (p. 85)

Using the above as a heuristic, I interpret the single connection in terms of direct instruction from teacher to student as producing 'mindlessly dull behavior' ${ }^{38}$ From too much richness in curriculum, a chaotic frame emerges. What one needs, from Kauffman's point of view and mine, are networks (or curricular structures) that 'achieve both stability and flexibility' (pp. 86 and passim). This notion of a structure or system that aims for stability and flexibility is one that has guided my curriculum designs and instructional strategies for the past decade. Obviously this 'and-ness' is in contrast to the Aristotelian logic which has dominated our intellectual thought for so many centuriesnamely that logic, epistemology, education should exhibit an either/or (right/wrong) frame. To quote Aristotle's famous phrase: 'An object cannot both be and not be at the same time'. The new science of complexity (Doll, et al., 2005) challenges this dichotomous split.

\section{Educational Implications}

In looking at the educational implications I see emerging from the new science of complexity (as well as from the new science of chaos theory), I'd like to go back to Ervin Laszlo's comments about a systems view and 'organized complexity'. In these comments, he mentions (back in the 1980s) that a systems view is the one emerging around organized complexity, a step ahead of the Newtonian/modernist view of organized simplicity, and two steps ahead of the pre-modernist 'classical world views of divinely ordered [and] imaginatively envisaged complexity' (the quote with which I introduced the previous section, Complex Organization). In focusing on organized complexity--Katherine Hayles' 'disorderly order'-Laszlo helps us see contemporary complexity theory's relation to biological, open systems, whence complexity theory emerged. A focus here, I'd say the key focus, is that of relations. The heart of a systems view is one of relations. While relations exist in both pre- modern and modern frames, in neither of these do they take on the dominant role. In a pre-modern world, it is ritual that is dominant; and in a modern world it is observation-reality is what an 'eyewitness' sees. But as I quote in endnote 18, in our contemporary, post-modern world, 'observation disappears in favor of [patterned or webbed] relations': 'relations and their patterns replace observation and its data collection'. Relations then become, to

\footnotetext{
${ }^{38}$ Obviously a brilliant, even a good teacher, can deliver an outstanding lecture or lesson. Still in this model there is usually a certain passivity on the part of the student (the receiver of knowledge). The subject and object are still split and there is not, to use the phrase of Jardine et al., a 'living of the world together'. Those wishing to embrace complexity (and not all will) will move toward Jardine's frame.
} 
paraphrase Whitehead, the 'really real'. More than just this, relations, in terms of similarities and differences, become the focal point for a developing epistemology. Such an emerging epistemology is aided, indeed guided, by comments made by Bateson, Kauffman, and Whitehead. Once one moves from data collection to relationships, one also moves from isolated facts (with all their 'inertness') to interconnected or webbed patterns (with their ongoing 'aliveness'). Such a switch of focus is illustrated by the way in Fritjof Capra's The Web of Life (1996) lies at the heart of complexity science's worldview (Davis \& Sumara, 2006).

At the university or college level this has meant for me a caution in using too rigid a syllabus-instead using one which is 'rich' (Doll, 1993, ch. 7) in problematics. The power inherent in such richness is brought forth as students-individually or in groups-work on various texts which web together into a frame that combines closure with openness, a modest rigidity with a structured flexibility. As students work on these various texts, the aim is not for all to be on the same page at the same time but, contrarily, for groups within the web to be on different pages, in different texts, at the same time. Embracing complexity, the aim is for a process of cross- fertilization, pollination, catalyzation of ideas. Over time (an important ingredient for both Prigogine and Kauffman) a network of connections and interconnections becomes more and more webbed. Learning now occurs, not through direct transmission from expert to novice, or from teacher to student, but in a non-linear manner through all in a class exploring a situation/problem/issue together (and indeed from multiple perspectives). In Jardine et al.'s (2003) phrase, a community of learners is now 'living the world together'. The teacher's role in this community of learners becomes that of both 'planting a seed' and taking a lead (but not overly dominant) role in fertilizing the seed that it may grow (Dewey) to eventually pollinate and catalyze other ideas. In other words, the curriculum (with its expression in a syllabus) is now an emerging one within an ongoing process that actually catalyzes itself via interactions within the system or network. In Kauffman's terms, order now appears freely and naturally (indeed expectedly). Such order is not imposed, as has been the history of curriculum development from Ramus to Tyler to the present day. Order emerges from interactions having just the 'right amount' of tension or difference or imbalance among the elements interacting. Such a 'right amount' cannot be specified; it can only be felt or intuited, or to use Whitehead's (1929/1978) term 'prehended' (ch. 2 and passim).

In schooling situations $(\mathrm{K}-12)$, where rigid impositions are more common and more defined, other strategies are needed-strategies which can achieve the 'right amount' of interaction among students, teachers, ideas. Two classroom examples might help here. In one third grade classroom the teacher handed out a worksheet which had the following on it:

$$
\text { P I - - O W }
$$

The task of the students was to fill in the two blanks with the same letter. The students quickly choose $\mathrm{L}$ as the missing letter and the teacher was then prepared to move on to the next example. I asked her to stop a minute and let us explore (complexify) this example. Quite nervous, the teacher agreed-fearful I believe of losing control, especially to a university professor who had just dropped by to observe the two student interns he had placed in the class. I asked the students to find words they could 'see' within the word PILLOW. The class came alive; even the teacher entered. Along with the usual words seen (such as low, plow, pill, ill, po, pi, lip, will, I, pow, poll) we encountered the situation of determining whether WOP, a slang word for one of Italian descent, was allowed. My contribution of Po and PO sent us to the dictionary, which in turn raised the issue of P.O. and P.O.W. Already the learning (on which we had by now spent maybe three minutes) was raised to a new level-with all taking part quite 
wholeheartedly and even heatedly. To further complexify, I arranged the words chosen in a pattern-two letter words, three letter words, etc. along with those which proceeded in a linear fashion (low) and those which did not (will). New levels of organization arose spontaneously and immediately-my categorization was challenged (as it should have been) and seen as only one of a number of categorizations. Again, the 'time on task' here was no more than a total of five minutes; five minutes that led us into expanded vocabulary, word play, definitions, rules, categorizations. While I would not wish to draw a cause-effect relationship between studying complexity theory in my doctoral seminars and working with (third) grade students in the teacher- education program I direct, I would say that complexity theory (the study of self-organizing systems) has helped me to 'see' beyond the obvious, into that not-yet-seen.

Another example comes from a first grade classroom and has potential to be used in a recursive way through most of the elementary grades and to integrate art with mathematics, as well as to bring in the use of hand-held computers. In this grade (actually Kindergarten in May) the teacher wished the students to have a feel for whole digits that would add up to six: $4+2,1+5,3+3$, etc. She did this by having oblong disks, red on one side and white on the other. As the students, following her directions (little deviation allowed), would turn over the disks to see four red and two white she would then ask how many disks in all (six, of course). This went on for a while and (again) I asked if we might, as a class, play a bit with the disks. Although horrified (not just worried, but horrified) the teacher acquiesced. I asked the students to make whatever combinations they wished of the six disks in from of them. Some did Red, White, Red, White, Red, White (not all did six combinations but that was alright with me at this stage). Since I write poorly I asked if I could use an R for red and a W for white. There was quick agreement and soon we had such combinations as-:

$$
\begin{aligned}
& \mathrm{R}+\mathrm{R}+\mathrm{R}+\mathrm{W}+\mathrm{W}+\mathrm{W} . \\
& \mathrm{R}+\mathrm{R}+\mathrm{W}+\mathrm{R}+\mathrm{R}+\mathrm{W} .
\end{aligned}
$$

With this last combination I asked how many R's and how many W's, and we agreed on: 4 R's + 2 W's.

With these students I (almost) left the exercise at this. I did, though, ask the class if anyone could find a combination if we had two of the six disks colored blue. One brighteyed little girl said, 'Then we could have:

$$
\mathrm{R}+\mathrm{W}+\mathrm{B}+\mathrm{R}+\mathrm{W}+\mathrm{B} \text {. }
$$

I gave the girl a hug and told the teacher, 'Now I am out of here'. I understand from others she talked of the brilliance of her class and what it was able to accomplish for a whole year after this.

It is obvious that much more than combinations and permutations sit within the six disk framework. One could easily arrange the combinations in a system form:

$$
\begin{aligned}
& 6+0 \\
& 5+1 \\
& 4+2 \\
& 3+3 \\
& 2+4 \\
& 1+5 \\
& 0+6
\end{aligned}
$$

Starting at the bottom $(0+6)$ and counting up the left column, one comes to $7+$ ? The closed system $(0+6$ to $6+0$, counting only whole digits $)$ immediately is opened with the $7+$ ?. Either subtraction or negative numbers emerge. Currently our intern students are working on this relationship with their first and second grade classrooms--on a number line, the numeral zero becomes important; it is not 'nothing'.

The six disk objects, of course, do not need to be arranged in a linear or boxed order. Transforming the oblong disks into circles one can arrange the six as is done in bowling: 
000

The addition of another row gives one the 'ten-pins' of bowling as well as Pascal's triangle, which itself can be transformed into $a, a^{2}, a^{2}+2 a b+b^{2}$, etc. The next line, that of the four circles (the last in the bowling sequence), is of course a trinomial.

If one wishes to go further with this pattern, the Fibonacci sequence can be found to exist within Pascal's triangle. Looking at the difference between the digits in the sequence $(1,1,2,3,5,8$, etc.) one can find this difference attracting itself to 666 or 1.666 (depending on which numeral one wishes to call the denominator).

This attraction is, as is well-known, the 'perfect form' which shows up in the architecture of the Parthenon or the proportions of medieval art. ${ }^{39}$ Here mathematics in all its beauty and art/architecture in all its (western) beauty intertwine. (Asian and African 'beauty' have different forms.)

As I have said, I would not claim a cause-effect relation between studying complexity theory and teaching for 'that yet-to-be-seen'. I will, though, state my personal experience based on over a half-century of teaching-the study of complexity has opened my eyes to that which I did not see before (to a new and livelier sense of method, one based on seeing more and seeing from multiple perspectives). I now regularly ask myself when I enter a classroom (at any level),

'What can I learn today from this experience?' And I ask of those I am privileged to teach, 'Can you see another way to do/read/interpret what we have just done?' Combined with my personal metaphysical views, also developed while I have been studying complexity theory, I now begin to envision education as:
A fascinating imaginative realm,
Born of the echo of God's laughter,
Where no one owns the truth,
And everyone has the right to be understood.
(Milan Kundera, 1988)

\section{References}

Bak, P. (1996). How Nature Works. New York: Springer-Verlag.

Bateson, G. (1979). Mind and Nature: A necessary unity. New York: Bantam.

Bertalanffy, L. von (1968). General System Theory. New York: Braziller).

Bertalanffy, L. von (1981). A Systems View of Man (P. LaViolette, ed.) Boulder, CO: Westview Press.

Brockman, J. (1995). The Third Culture. New York: Simon \& Schuster.

Bronowski, J. (1978). The Common Sense of Science. Cambridge, MA: Harvard University Press.

Burtt, E. A. (1932/1955). The Metaphysical Foundations of Modern Physical Science. New York, Doubleday.

Capra, F. (1996). The Web of Life. New York: Doubleday.

Davidson, M. (1983). Uncommon Sense. Los Angeles: Tarcher.

Davis, B. \& Sumara, D. (2006). Complexity and Education. Mahweh, NJ: Erlbaum.

Dear, P. (1995). Discipline and Experience. Chicago: University of Chicago Press.

Doll, W. (1993). A Post-Modern Perspective on Curriculum. New York: Teachers College Press.

Doll, W. \& Gough. N. (eds.) (2002). Curriculum Visions. New York: Lang.

Doll, W., Fleener, M. J., Trueit, D. \& St. Julien, J. (eds.) (2005). Chaos, Complexity, Curriculum and Culture. New York: Lang.

Fleener, M. J. (2002). Curriculum Dynamics: Recreating Heart. New York: Lang.

Gary, K. (2006). Leisure, Freedom, and Liberal Education, Educational Theory, 56(2), 121-136.

Gleick, J. (1987). Chaos: Making a New Science. New York: Viking.

Grafton, A. \& Jardine, L. (1986). From Humanism to the Humanities. London: Duckworth.

Hamilton, D. (1989). Towards a Theory of Schooling. London: Falmer.

Hamilton, D. (1990). Curriculum History. Geelong, VIC: Deakin University Press.

\footnotetext{
${ }^{39}$ Mario Livio (2002) has a fascinating book on this intersection of mathematics and art, including our misreading (as he sees it) of that relationship.
} 
Hamilton, D. (1992). Comenius and the New World Order. Comenius, 46, 157-171.

Hamilton, D. (2003). Instruction in the Making: Peter Ramus and the beginnings of modern schooling. Paper presented at 2003 American Educational Research Association.

Hayles, N. K. (1990). Chaos Bound. Ithaca, NY: Cornell University Press.

Hayles, N. K. (1991). Chaos and Order. Ithaca, NY: Cornell University Press.

Hayles, N. K. (1999). How We Became Posthuman. Chicago: University of Chicago Press.

Holton, D. \& May, R. (1993). Chaos and One-Dimensional Maps. In T. Mullin (ed.), The Nature of Chaos. New York: Oxford University Press.

Jaeger, S. J. (1994). The Envy of Angels. Philadelphia: University of Pennsylvania Press.

Jardine, D., Clifford, P. \& Friesen, S. (2003). Back to the Basics of Teaching and Lear ning. Mahweh, NJ: Erlbaum.

Jardine, D., Clifford, P. \& Friesen, S. (2006). Curriculum in Abundance. Mahweh, NJ: Erlbaum.

Johnson, G. (1996). Fire in the Mind. New York: Vintage Books.

Kanigel, R. (1997). The One Best Way: Frederick Winslow Taylor and the enigma of efficiency. Harmondsworth: Penguin.

Kauffman, S. (1993). The Origins of Order. New York: Oxford University Press.

Kauffman, S. (1995). At Home in the Universe. New York: Oxford University Press.

Kauffman, S. (2000) . Investigations. New York: Oxford University Press.

Kliebard, H. M. (1995) The Tyler Rationale Revisited. Journal of Curriculum Studies, 27(1), 81- 88.

Kundera, M. (1988). The Art of the Novel (L. Asher, trans.) New York: Grove Press.

Laszlo, E. (1972). The Systems View of the World. New York: Braziller.

Livio, M. (2002). The Golden Ratio: The story of Phi, the world's most astonishing number. New York: Broadway Books.

Lorenz, E. (1963). Deterministic Nonperiodic Flow. Journal of the Atmospheric Sciences, 20, 130 -141.

Lorenz, E. (1995). The Essence of Chaos. Seattle: University of Washington Press.

Mullin, T. (ed.) (1993). The Nature of Chaos. Oxford: Clarendon.

Ong, W. (1958/1983). Ramus, Method, and the Decay of Dialogue. Cambridge, MA: Harvard University Press.

Osberg, D. (2005). Emergent Knowledge: A Response to Jacques Daignault's 'Hacking the Future', Proceedings of the Complexity Science and Educational Research Conference, November 20 -22, Loranger, LA, pp. 5-8, www.complexityandeducation.ca

Oxford English Dictionary (2005). OED Online: http:/ / dictionary.oed.com.ezproxy.library.lsu

Peirce, C. S. (1931). Collected Papers of Charles Sanders Peirce, Vols. 1-VI, C. Hartshorne \& P. Weiss, eds. Boston: Belknap.

Prigogine, I. (1961). Introduction to the Ther modynamics of Ir reversible Processes (2nd rev. ed.). New York: Wiley.

Prigogine, I. (1997). The End of Certainty: Time, Chaos, and the New Laws of Nature. New York: The Free Press.

Prigogine, I. \& Stengers, I. (1983). Postface. In M. Serres, Hermes. Baltimore: Johns Hopkins University Press.

Prigogine, I. \& Stengers, I. (1984). Order Out of Chaos. New York: Bantam.

Reiss, T. (1982). The Discourse of Modernism. Ithaca, NY: Cornell University Press.

Serres, M. (1983). Hermes: Literature, Science, Philosophy (J. Harari \& D. Bell, trans.). Baltimore: Johns Hopkins University Press.

Serres, M. \& Latour, B. (1995). Conversations on Science, Culture, and Time (R. Lapidus, trans.). Ann Arbor: University of Michigan Press.

Smitherman, S. (2006). Reflections on Teaching a Mathematics Education Course. Louisiana State University Doctoral Dissertation.

Smolin, L. (2001). Three Roads to Quantum Gravity. New York: Basic Books.

Stanley, D. (2005). Paradigmatic Complexity. In W. Doll et al. (eds.), Chaos, Complexity, Curriculum and Culture. New York: Lang.

Stevens, W. (1982). Extracts on addresses to the academy of fine ideas. In Wallace Stevens: The collected poems. New York: Vintage Books.

Stewart, I. (1990). Does God Play Dice? Oxford: Blackwell.

Triche, S. \& McKnight, D. (2004). The Quest for Method: The legacy of Peter Ramus. History of Education, 33(1), 39-54.

Trueit, D. (2005). Complexifying the Poetic: Toward a poiesis of curriculum, Louisiana State University Doctoral Dissertation.

Trueit, D. (in preparation). Beyond Simple Order: Politically correct curriculum. Paper in preparation for presentation to AERA, Chicago, 2007.

Waddington, C. H. (1957). The Strategy of the Genes: A discussion of some aspects of theoretical biology. New York: Macmillan. 
WILLIAM E. DOLL, JR.

Weber, M. (1996). The Protestant Ethic and the Spirit of Capitalism (T. Parsons, trans.) Los Angeles: Roxbury.

Whitehead, A. N. (1929/1967). The Aims of Education and Other Essays. New York: Free Press.

Whitehead, A. N. (1929/1978). Process and Reality: An essay concerning cosmology (D. Griffin \& D. Sherburne, eds.) New York: Free Press.

\section{About the Author}

William E. Doll Jr. is Emeritus Professor of Educational Theory, Policy, and Practice at LSU. He has published for decades in the fields of educational curriculum and instruction. He has played major roles in three books: A Post-Modern Perspective on Curriculum, Curriculum Visions, and Chaos Complexity Curriculum and Culture. He has a strong international interest, is a founding member of the Chaos and Complexity SIG, and is a recipient of AERA's Division B Lifetime Achievement Award.

(c) Copyright 2012, by William E. Doll, Jr. The author, William E. Doll, Jr., assigns to the University of Alberta and other educational and non-profit institutions a non-exclusive license to use this document for personal use and in courses of instruction provided that the article is used in full and this copyright statement is reproduced. The authors also grant a non-exclusive license to the University of Alberta to publish this document in full on the World Wide Web, and for the document to be published on mirrors on the World Wide Web. Any other usage is prohibited without the express permission of the authors.

This work first appeared in Educational Philosophy and Theory, Vol. 40, No. 1, 2008. 